\title{
O INSTITUTO DO COMPLIANCE AMBIENTAL NO CONTEXTO DA SOCIEDADE PLURISSISTÊMICA
}

Marcio Luis Oliveira

Doutor e Mestre em Direito. Professor da Faculdade de Direito da Universidade Federal de Minas Gerais (UFMG), da Escola Superior Dom Helder Câmara (Mestrado e Graduação) e da Faculdade Milton Campos (Mestrado e Graduação). Advogado e Consultor Jurídico. Email: marcio.luis@uol.com.br

Beatriz Souza Costa

\begin{tabular}{r}
\hline Mestre e Doutora em Direito Constitucional pela UFMG. Pós Doutorada na Univ. \\
Castilla-La Mancha, Espanha. Professora da Pó-Graduação do Curso de Mestrado \\
em Direito Ambiental e Desenvolvimento Sustentável da Escola Superior Dom Helder \\
Câmara. Pró-Reitora de Pesquisa da ESDHC. \\
Email: biaambiental@yahoo.com.br
\end{tabular}

\section{RESUMO}

$\mathrm{O}$ artigo tem por objetivo analisar o instituto do compliance ambiental e socioeconômico, como instrumento de formação e de afirmação de uma cultura de integridade sustentável. Para a abordagem do tema, o instituto do compliance foi contextualizado na sociedade plurissistêmica e considerado como instrumento de boa governança e de gestão social. Na elaboração do trabalho, foram utilizadas as metodologias teórico-analítica e especulativa.

Palavras-Chave: compliance ambiental; sustentabilidade; governança; gestão social; sociedade plurissistêmica 
THE INSTITUTE OF ENVIRONMENTAL COMPLIANCE IN THE CONTEXT OF THE PLURYSYSTEMIC SOCIETY

\begin{abstract}
This article aims to analyze the environmental and socioeconomic compliance institute as an instrument of formation and affirmation of a culture of sustainable integrity. In order to approach the theme, the compliance institute was contextualized in the plurysystemicsociety and as an instrument of good governance and social management. In the elaboration of the work the theoretical-analytical and speculative methodologies were used.
\end{abstract}

Keywords: environmental compliance; sustainability; governance; social management; plurysystemic Society. 


\section{INTRODUÇÃO}

A sociedade contemporânea é altamente plural, complexa e dinâmica. Nessa sociedade, vive-se sob sistemas normativos diversos e coexistentes. Assim, atividades empreendedoras, públicas ou privadas devem se adequar a realidades normativas e processuais de naturezas muito distintas.

A multiplicidade dos sistemas normativos dificulta a adequação das atividades empreendedoras ao que delas é exigível, nos contextos jurídico, ético, técnico-científico, dentre outros. Portanto, adequar-se às normas externas, em sua pluralidade sistêmica, exige das atividades empreendedoras um esforço para criar internamente normas substantivas e processuais que possam racionalizar e otimizar o empreendedorismo de maneira a alcançar maior accountability e responsiveness perante a sociedade, o Estado, a comunidade científica, os fornecedores e os consumidores. Tal esforço se desvela no instituto do compliance, tema desse artigo no viés da sustentabilidade.

Nesse sentido, o artigo tem, como tema-problema, a seguinte indagação: o instituto do compliance, na seara da sustentabilidade, pode ser fator para a afirmação de uma nova cultura econômica?

De modo a responder o tema-problema, o artigo tem como marco teórico a noção de sociedade plurissistêmica (a partir das concepções de Niklas Luhmann) e os institutos da governança, da gestão social e do compliance. Como hipótese, o artigo avalia o instituto do compliance como elemento capaz, ou não, de promover a afirmação da cultura de integridade no campo da sustentabilidade.

Como objetivo geral, o artigo busca analisar o instituto do compliance como instrumento de boa governança e de gestão social, numa concepção plurinormativa. Como objetivo específico, o artigo discorre sobre o instituto do compliance na seara da sustentabilidade ambiental e socioeconômica. Na elaboração do trabalho, foram utilizadas as metodologias teórico-analítica e especulativa.

Além da introdução e das considerações finais, o artigo está organizado em três tópicos. No primeiro, é abordado o instituto do compliance no contexto da pluralidade sistêmica normativo-institucional. No item seguinte, faz-se uma análise do instituto do compliance como elemento de governança privada e pública e de gestão social. No último tópico, discorre-se sobre o compliance ambiental. 


\section{O INSTITUTO DO COMPLIANCE NO CONTEXTO DA PLURALIDADE SISTÊMICA NORMATIVO-INSTITUCIONAL}

O instituto do compliance se revela por métodos de adequação - pela adoção de normas e processos internos - da atividade empreendedora privada e pública aos sistemas jurídico, técnico-científico e ético que lhes sejam concernentes. O compliance, que teve origem no direito corporativo-financeiro estadunidense no início do século XX, tem, atualmente, aplicação em diversas áreas dos setores privado e público (WALKER, 2016).

Por intermédio do compliance, a pessoa jurídica cria internamente um conjunto de normas e procedimentos, com a finalidade de alcançar e manter maior grau, de conformidade com os sistemas normativos a que está sujeita em suas atividades, como os sistemas jurídico, ético e técnico-científico. Assim, a pessoa jurídica estabelece critérios substantivos e formais de prevenção, controle e responsabilização de práticas inadequadas e de potencial repercussão negativa interna e, sobretudo, externa. Nesse sentido, o compliance resulta em maior accountability e responsiveness da atividade empreendedora, o que, de alguma maneira, contribui para a sua higidez e eficiência funcional e finalística.

Pelo aperfeiçoamento dos métodos internos de accountability (monitoramento e responsabilização), a pessoa jurídica amplia suas capacidades de controle estrutural e operacional, tornando-se, por conseguinte, mais competente em seu planejamento estratégico, para evitar, amenizar e solver problemas (SEBRAE, 2018). Paralelamente, são também introduzidos mecanismos para qualificar suas habilidades de resposta (responsiveness) às demandas e expectativas de fornecedores, financiadores, consumidores, Estado e sociedade.

Por conseguinte, a institucionalização de sistemas de compliance eleva a credibilidade estrutural, funcional e conjuntural da pessoa jurídica, fortalecendo sua higidez (vitalidade do empreendimento) e eficiência na produção de bens ou prestação de serviços. Logo, o instituto do compliance, em suas várias modalidades, atua como importante instrumento de precaução, avaliação, correção e revisão das políticas de gestão de empreendimentos privados e públicos.

Sob essa perspectiva - e no cenário de pluralidade, complexidade e dinamicidade da sociedade pós-industrial (OLIVEIRA, 2016) -, o instituto do compliance revela-se como meio de conexão entre 
as tensões das autonomias privadas (entre si) e entre estas e a autonomia pública, constituindo-se, portanto, como elemento de boa governança para os setores público e privado, na interação entre a atividade empreendedora pública ou privada com a sociedade (WILSON, 2000).

Resta evidente que, na sociedade pós-industrial e de interconexões globais, as relações entre indivíduos, sociedade civil difusa, sociedade civil organizada, iniciativa privada e Estado se realizam em níveis crescentes de pluralidade, complexidade e dinamicidade. Destarte, responder às múltiplas expectativas e demandas, bem como adequarse às diversas instâncias de normatividade e de institucionalidade a que está sujeita qualquer atividade empreendedora (privada ou pública), requer acessibilidade e manuseio qualificado de informações precisas e constantemente atualizadas. Desse modo, o instituto do compliance, em suas várias nuances, cumpre a função de internalizar e de tornar compreensível aos empreendedores públicos e privados o universo de normas e de processos aos quais suas atividades precisam se conformar.

$\mathrm{O}$ instituto do compliance permite, pois, a racionalização e a otimização de práticas internas a serem adotadas na atividade empreendedora, em suas variadas estruturas e funções, dando ensejo a uma cultura de integridade (CGU, 2018) ou de sinergia comportamental adequada à multiplicidade sistêmica que caracteriza a sociedade contemporânea, aqui identificada sob o modelo teórico Luhmanniano:

Há muitas teorias que buscam definir a sociedade, em diversas áreas do conhecimento. E qualquer opção por uma delas revela-se insatisfatória. Porém, para efeitos deste trabalho, adota-se uma compreensão de sociedade fundada na Teoria dos Sistemas, de Niklas Luhmann, para quem a sociedade desvela-se como plexo comunicacional, ou seja, uma rede de comunicações complexas, plurais, dinâmicas e intergeracionais que atribuem sentido em diversas dimensões constitutivas da sociabilidade, como o senso de religiosidade, de moralidade, de eticidade, de estética, de politicidade, de economicidade, de juridicidade, de cientificidade (LUHMANN, 2007, apud COSTA; MATA DIZ; OLIVEIRA, 2018 p. 162).

Diante dessa complexidade de interconexões sistêmicas, a atividade empreendedora privada ou pública necessita de expertise na construção e consolidação da cultura de integridade - ou de sinergia comportamental - para realizar a contento suas atividades e finalidades. Pela cultura de integridade, a atividade empreendedora faz inserir em seu 
planejamento elementos que podem reduzir significativamente os riscos e os impactos da má gestão, pela inobservância de normas e procedimentos a que está condicionada pela diversidade sistêmica da sociedade.

Utilizando-se do instituto do compliance, a pessoa jurídica exerce, por conseguinte, sua autonomia para estabelecer normas e procedimentos de adequação a parâmetros éticos, jurídicos, técnicocientíficos, econômicos, dentre outros. Logo, a pessoa jurídica se capacita para autorregular-se de modo a atender à pluralidade sistêmica e às múltiplas demandas e expectativas. Ao aprimorar sua rede de compliance, a pessoa jurídica eleva a qualidade de sua atuação interna e externa por meio de interconexões sistêmicas e, simultaneamente, adquire e amplia seu "capital cultural e mercadológico", pela integridade comportamental, o que acaba resultando até mesmo na sua valorização institucional em diversas áreas.

No macrocontexto, o instituto do compliance atua de maneira a promover a sinergia comportamental de todo um setor privado (ex.: atividade minerária) ou público (ex.: rede hospitalar), o que resulta em benefícios sociais, econômicos, políticos, jurídicos, técnico-científicos, éticos, ambientais etc. Por óbvio, se várias pessoas jurídicas de um mesmo segmento privado ou público assumirem normas e procedimentos internos de adequação plurissistêmica (ex.: Direito, Ética, Ciência e Tecnologia), todo aquele setor será positivamente impactado. E, se tal prática se estender aos vários segmentos privados e públicos, o universo da sociedade será igualmente favorecido pela melhoria na prestação de serviços ou na produção e comercialização de bens de consumo.

A conjugação da afirmação e do exercício da autonomia da pessoa jurídica (autonomia privada e autonomia pública) com a potencialidade de interconexões plurissistêmicas (Direito, Ética, Ciência e Tecnologia) torna o instituto do compliance, em suas várias modalidades, um vetor importante para equacionar, de modo democrático, as tensões entre as autonomias privadas (entre si) e entre estas e a autonomia pública. Além disso, as interconexões possíveis e estimuláveis pelo instituto do compliance podem atuar, de modo expressivo, no desenvolvimento normativo e institucional, também dos múltiplos sistemas sociais, a médio e longo prazos; ou seja, se vários setores públicos ou privados aperfeiçoarem suas atividades internas de accountability e de responsiveness, a sociedade será positivamente impactada.

Sob essa ótica, os sistemas ético, jurídico, técnico-científico, econômico e político podem, por exemplo, se sujeitar a críticas e revisões 
advindas da reflexão e da experiência privada e pública, que os tornem ainda melhores. Por sua vez, o aperfeiçoamento dos sistemas sociais retroalimenta e requalifica a própria autonomia privada e pública, em suas funções normativa e institucional. Observa-se, assim, um ciclo de sinergia comportamental virtuoso entre os sistemas sociais e a afirmação da autonomia tanto pública quanto privada.

\section{O INSTITUTO DO COMPLIANCE COMO ELEMENTO DE GOVERNANÇA PRIVADA E PÚBLICA E DE GESTÃO SOCIAL}

Conforme já mencionado, o instituto do compliance teve origem no setor corporativo privado estadunidense, no início do século XX. Nessa qualidade, o instituto sempre foi considerado como objeto de reflexão e referência de governança para as pessoas jurídicas de direito privado, no exercício de sua autonomia privada.

Entretanto, e em razão da complexidade sistêmica desvelada na sociedade pós-industrial, o instituto do compliance não se limita mais ao setor privado, sendo de grande potencialidade também para a governança no setor público estatal, no exercício de suas funções peculiares (funções legislativa, administrativa, jurisdicional e de fiscalização).

No âmbito privado, o instituto do compliance insere-se na temática da governança corporativa, que é

[...] um conjunto de princípios ou mecanismos que norteiam o processo decisório em uma organização, a fim de que a mesma torne-se sustentável economicamente e confiável para seus stakeholders (acionistas, investidores, executivos) e se minimizem os 'problemas de agência'. Assim, 'as boas práticas de governança corporativa têm a finalidade de aumentar o valor da sociedade, facilitar seu acesso ao capital e contribuir para a sua perenidade'(IBGC, 2006:6).

Assim, pode-se compreender a governança corporativa basicamente como a criação de estruturas internas e externas que garantem que as decisões tomadas no âmbito organizacional sejam tomadas dentro de parâmetros que garantam os interesses dos acionistas/governantes/cidadãos, além de garantir a transparência das transações para as partes envolvidas.

$[\ldots]$

Dessa forma, a governança corporativa cria mecanismos, estruturas e incentivos que compõem o sistema/modelo de controle de gestão da corporação e direciona o comportamento dos gestores para a execução dos objetivos organizacionais, além de 
abastecer a alta administração com recursos empresariais que permitam identificar os riscos que são relacionados ao negócio (MARTIN et al., 2004, apud MENDONÇA; GUERRA; SOUZA NETO; ARAÚJO, 2013, p. 446).

Constata-se, portanto, que a governança corporativa está relacionada à gestão da pessoa jurídica na sua capacidade de planejamento, decisão, implementação, avaliação e revisão de suas práticas internas e externas, e com o objetivo de garantir a sustentabilidade multidimensional do empreendimento. Deste modo, e na conjuntura da sociedade plurissistêmica, o instituto do compliance se torna essencial para a governança corporativa ao servir, sobretudo, como fator de prevenção e de correção eficiente de problemas normativo-institucionais que, uma vez ocorrendo, podem interferir substancialmente na sustentabilidade setorial ou até global do empreendimento.

Ademais, o instituto do compliance pode ser eficazmente utilizado por associações de segmentos privados (ex.: confederações de empresas de determinado setor econômico) como meio para se autopositivar "códigos de condutas" para todo aquele setor.

Nessa hipótese, toda a atividade privada se autorregula e se autoinstitucionaliza sob critérios comuns e específicos de cada setor. Aliás, o exercício associativo da autonomia privada setorial (ex.: autorregulação por meio da associação de empresas mineradoras), como instância para a normatização de parâmetros e diretrizes de condutas, revela-se altamente eficiente em sistemas democrático-participativos, cabendo ao Estado, com a cooperação dos cidadãos e da sociedade civil organizada, as funções de fiscalização e de correção das normas setoriais, por meio do controle de legalidade, convencionalidade ou constitucionalidade. A prática da autorregulação setorial, como expressão da autonomia privada, contribui para a ação consciente e responsável dos segmentos privados e favorece a afirmação da cultura de integridade ou de sinergia comportamental, sob a constante fiscalização da sociedade e dos órgãos competentes do Estado.

No âmbito da governança privada, a adoção de modelos de compliance se respalda, primária e fundamentalmente, nos sistemas jurídicos estatal e internacional. O Direito, como sistema normativo da sociedade, oferece uma variedade de regimes jurídicos aos quais a atividade empreendedora deve se submeter. Normas constitucionais, administrativas, tributárias, previdenciárias, trabalhistas, empresarialistas, civilistas, penais, ambientais, consumeristas, concorrenciais, financeiras, 
contábeis, registrais, autorais e até eleitorais são apenas alguns exemplos da diversidade e da especialização que os sistemas jurídicos contemporâneos alcançaram. E essa multiplicidade normativa ainda se torna mais complexa quando, agregado ao Direito interno, houver regimes jurídicos positivados pelo Direito Internacional em áreas especializadas, como o meio ambiente, a concorrência, o mercado de trabalho, as marcas e patentes.

Contudo, o Direito não é e nem deve ser o único sistema impulsionador do instituto do compliance. Na sociedade plurissistêmica, diretrizes éticas, políticas, econômicas, técnico-científicas, dentre outras, precisam ser consideradas pelo empreendedorismo privado para que a cultura de integridade ou de sinergia comportamental possa se constituir como patamar de qualificação das relações do setor privado com as expectativas e demandas dos cidadãos, da sociedade, da ciência e da tecnologia, do Estado e de outros segmentos privados, em níveis locais, regionais, nacionais e internacionais.

Desse modo, há um conjunto de normas e de processos que a atividade privada pode internalizar, mesmo que não previstos no Direito. Normas para aprimorar o grau de resposta (responsiveness) das expectativas e demandas éticas e técnico-científicas são, via de regra, relevantes para a própria sustentabilidade da atividade empreendedora; especialmente num ambiente social repleto de meios de intercomunicação instantâneos, como as redes sociais.

Logo, o mal atendimento ao consumidor ou a obsolescência tecnológica podem comprometer a capacidade de resposta (responsiveness) do empreendimento, além de submetê-lo a uma eventual responsabilização (accountability), com consequências imprevisíveis a médio e longo prazos. Responsabilização que não se limita a penalidades jurídicas, mas econômicas, como a perda de clientela, a carência de fornecedores e a inviabilização de financiamentos, além de fomentar dissidências e disputas acionárias com graves prejuízos para a governança do empreendimento.

Mas, como já ressaltado, o instituto do compliance não é aplicável apenas na governança dos segmentos privados, com ou sem finalidade econômica. No que concerne ao setor público estatal, o instituto do compliance assume especial relevância na sociedade plurissistêmica, em que o Estado - ainda que respaldado pela soberania político-jurídica não detém mais o monopólio da referencialidade normativo-institucional da dinâmica pública.

Dessa forma, internamente, o Estado continua a ser uma 
importante instância de integração, negociação e mediação da pluralidade social e da dinâmica de poder, além de prestador de serviços públicos e fornecedor de certos bens; mas, compartilha, cada vez mais com a sociedade civil organizada e com a iniciativa privada, as funções estatais que, na fundação da modernidade, lhe foram atribuídas com exclusividade. Internacionalmente, a soberania do Estado encontra-se relativizada por normas e instituições de alcance global, submetendo-se, ainda, a um processo histórico e acelerado de integração de suas funções e ações com outros Estados, organizações e organismos internacionais. Logo, a soberania estatal, outrora tida como absoluta, se mostra, atualmente, compartilhada tanto interna quanto internacionalmente (OLIVEIRA, 1999).

Sabe-se que, na contemporaneidade, são muitas as funções de Estado, dentre as quais se destacam: a legislativa, a governativa, a administrativa, a fiscalizadora, a jurisdicional, a coercitiva, a presentativa e a representativa (OLIVEIRA, 2016). Afora a função legislativa - pela qual o Estado positiva regimes jurídicos, observando e cumprindo os parâmetros normativo-constitucionais -, todas as demais funções se pautam por algum grau de adequação - vinculação ou discricionariedade - à normatividade constitucional, convencional e legal.

Todavia, a necessária conformação das funções de Estado à normatividade constitucional, convencional e legal não exime a governança pública do dever de se ajustar também a parâmetros e diretrizes comportamentais assinalados por outros sistemas sociais, como a eticidade, a cientificidade, a economicidade e a politicidade, com vistas, por exemplo, ao desenvolvimento socioeconômico e ambientalmente sustentável. E é nesse cenário que o Banco Mundial, já em 1992, estabeleceu que "governance is defined as the manner in which power is exercised in the management of a county's economic and social resources for development" (THE WORLD BANK, 1992, p. 1)1. Resta claro, por conseguinte, que quanto mais democrática for a sociedade, maior será a exigência de accountability e de responsiveness da governança pública estatal no exercício de suas funções de Estado, na prestação de serviços públicos e na produção e fornecimento de bens à sociedade, segundo critérios jurídicos, éticos, técnico-científicos, ambientais, dentre outros tantos.

1 Tradução livre: "governança é definida como a maneira pela qual o poder público, numa sociedade, é exercido na gestão dos seus recursos econômicos e sociais visando ao desenvolvimento". 
Por sua vez, é por intermédio da governança pública que o ciclo das políticas públicas se realiza e se desvela multifacetado, englobando as várias funções de Estado e visando à satisfação das diversas demandas e expectativas da sociedade plurissistêmica (CUSTÓDIO; OLIVEIRA, 2015). E, ao se considerar o Estado, na contemporaneidade, como um acervo institucional prestador de vários serviços públicos essenciais e produtor e fornecedor de outros tantos bens aos indivíduos, à sociedade e até à iniciativa privada, a concretização das funções estatais há que ser norteada pela boa gestão ou governança públicas.

Há que se ressaltar, ainda, que são crescentes as modalidades de parceria entre o Estado e a iniciativa privada e o terceiro setor na prestação de serviços públicos e na produção e fornecimento de bens. Concomitantemente, na sociedade plurissistêmica, o Estado tem tido a necessidade de especializar e institucionalizar cada vez mais suas funções de regulação e fiscalização dos inúmeros setores públicos e privados, com o intuito de acurar as suas capacidades de resposta às demandas e expectativas da sociedade (responsiveness) e de viabilizar o monitoramento técnico e democrático da atividade econômica e das próprias funções estatais (accountability). Desse modo, a própria noção de governança pública se amplia, como informa o Banco Mundial:

In general, this initiative will take as a starting point the five dimensions of good governance that was developed in the World Bank's Corruption study for Europe and Central Asia and contained in the Bank's most recent update of its public sector strategy: public sector management, competitive private sector, structure of government, civil society participation and voice, and political accountability.[2] This definition goes well beyond effective delivery of public services (even if that is a benchmark indicator of the quality of governance, a lightning rod for public sentiments about government, and a useful starting point for assessing the quality of governance).And it can also go well beyond the notion of "economic governance" which is typically the focus of most World Bank work on governance.(THE WORLD BANK, 2009) $)^{2}$

2 Tradução livre: "Em geral, adotam-se, como referência, as cinco dimensões da boa governança que foram desenvolvidas no estudo do Banco Mundial para a Europa e Ásia Central sobre o tema da corrupção, e atualizadas pelo Banco Mundial nos seus indicadores estratégicos para o setor público: a qualidade da gestão pública, a competitividade no setor privado, a estrutura de governo, a participação e voz da sociedade civil e o controle e responsabilidade política. Essa compreensão de governança transcende a questão da prestação efetiva de serviços públicos (mesmo que estes possam ser um critério para se avaliar a qualidade da governança e um parâmetro de aferição da percepção pública quanto ao governo), além de suplantar a noção de 'governança econômica', que é tipicamente o foco da maioria dos trabalhos do Banco Mundial sobre governança." 
Sociedades democráticas e em estágio de desenvolvimento socioeconômico avançado estão, atualmente, focadas na eficácia, eficiência e efetividade da gestão privada e pública, num ambiente democrático. Logo, nessa conjuntura de interconexão entre os setores público e privado com os múltiplos sistemas sociais, o instituto do compliance revela-se promissor como meio de formação e de afirmação da cultura de integridade ou de sinergia comportamental, para qualquer forma de empreendedorismo econômico ou social realizado pelo setor privado, pela sociedade civil organizada e pelo Estado.

Por isso, a governança pública não se limita mais ao viés gerencial que lhe foi exigido no final do século XX, como contribuição da governança privada e como meio para se alcançar a eficiência administrativa do Estado (BRESSER-PEREIRA, 1996). Hodiernamente, a governança pública foi aprimorada pela inclusão de elementos da gestão social, de modo a se democratizar em seus fundamentos e práticas, como informam Alcântara, Pereira e Silva:

Os princípios da transparência, da accountability e da responsabilização são acoplados a uma concepção democrática mais ampla. Estes, além do pluralismo, autonomia e participação, passam a ser princípios comuns na gestão social e na governança pública. Bevir (2011) realiza uma genealogia do conceito de governança democrática. $\mathrm{O}$ autor sugere a necessidade de uma renovação democrática por meio da participação pública e considera que a governança busca uma cidadania pluralista, uma democracia participativa e a elaboração de políticas públicas de forma dialógica (BEVIR, 2011). Nesse cenário, para Tenório et al. (2008, p. 2), “[...] a operacionalização da governança democrática combina a ação interorganizacional - reconhecida como um componente integral da efetivação de várias políticas". Assim, foi possível para Villela e Pinto (2009) afirmarem que existe relação entre a governança pública e a racionalidade comunicativa. Todavia, para isso, é preciso entender a governança pública como “[...] a prática de uma gestão compartilhada de processos decisórios que conduz, a partir do consenso, as deliberações de uma dada rede, objetivando articular e facilitar ações do projeto de desenvolvimento traçado pelos próprios participantes [...]" (VILLELA; PINTO, 2009, p. 1075) e, nesse caminho, governança participativa se refere a uma administração dialógica de coordenação dos atores. Especialmente, no que se refere à cidadania, a gestão social utiliza o conceito de cidadania deliberativa - que necessita para se consolidar de processos de discussão, inclusão, pluralismo, igualdade participativa, autonomia e bem comum (TENÓRIO et al., 2008; TENÓRIO, 2005; 2012, apud ALCÂNTARA; PEREIRA; SILVA, 2015, p. 20) 
Portanto, o instituto do compliance é instrumento importante para fortalecer a governança privada e pública, bem como para viabilizar a gestão social, de maneira a fomentar um círculo virtuoso na atividade empreendedora nas esferas privada e pública. Assim, e por instrumentos de compliance, poder-se-á alcançar substancial aprimoramento das atividades privadas - de mercado ou da sociedade civil organizada -bem como melhorar a qualidade das funções estatais, da prestação dos serviços públicos e da produção e fornecimento de bens públicos à sociedade, com observância de normas e processos jurídicos, éticos e técnico-científicos mais compatíveis com a accountability e a responsiveness demandadas pela sociedade plurissistêmica, em relação aos setores privados e estatais.

Dentre os vários tipos de compliance, a proteção ao meioambiente, no cenário do desenvolvimento sustentável, tem atraído especial atenção de múltiplos setores da sociedade contemporânea, em níveis locais, regionais, nacionais e internacional.

\section{COMPLIANCE AMBIENTAL}

A necessidade de geração de riqueza sob os fundamentos da inclusão socioeconômica, da melhoria da qualidade de vida e da proteção ambiental é tema do qual Estados, iniciativa privada e terceiro setor já não podem mais se eximir de considerar em suas atividades. As sociedades plurissistêmicas pós-industriais (altamente plurais, dinâmicas e complexas em suas tessituras e operacionalidades) têm, em maior ou menor grau, incorporado práticas mais sustentáveis em seus cotidianos. Por consequência, cidadãos e grupos sociais com maior consciência holística têm demandado por mudanças comportamentais das atividades empreendedoras privadas e públicas, de modo a afirmar uma cultura de integridade social, econômica e ambientalmente sustentáveis, nos níveis locais, regionais, nacionais e até internacional (SANDS; PEEL; FABRA; MACKENZIE, 2012).

Não é objeto deste trabalho abordar o recente processo histórico de formação e ampliação do novo paradigma civilizatório de desenvolvimento sustentável ocorrido a partir do século XX (COSTA; REIS; OLIVEIRA, 2016). Contudo, e uma vez considerado o paradigma da sustentabilidade, inúmeras são as normas e processos que pautam a agenda do desenvolvimento sustentável sobre o qual as noções de riqueza, de inclusão socioeconômica e de proteção ambiental são autoconstitutivos 
e interdependentes (HOLLAND, 2001, p. 390-401).

As noções de prevenção e de precaução quanto aos impactos da intervenção humana no meio-ambiente natural e social - sob os enfoques jurídico, ético e técnico-científico - têm norteado o ciclo econômico da produção, distribuição, repartição e consumo de bens e serviços (SOUZA, 2005) e o ciclo das políticas públicas (CUSTÓDIO; OLIVEIRA, 2015).

Nesse sentido, é importante se considerar que as noções de prevenção e precaução não se limitam à seara do sistema jurídico, mas também se estendem ao sistemas ético e técnico-científico. Logo, o instituto do compliance ambiental deve incorporar normas e procedimentos plurissistêmicos, de maneira a se compatibilizar com a cultura de integridade atualmente demandada, de modo crescente, pela sociedade também plurissistêmica.

Os planos gerenciais no âmbito das atividades privadas e a realização de políticas públicas na seara governamental não podem mais ser elaborados, implementados, avaliados e revistos sem incorporarem práticas de prevenção e de precaução exigidos pelos sistemas jurídico, ético e técnico-científico. Consequentemente, a conscientização e a internalização em relação a normas e procedimentos sobre eventuais e potenciais impactos negativos ambientais devem ser prioritariamente compreendidos e introduzidos na dinâmica do empreendedorismo privado e público sob a perspectiva da prevenção e da precaução.

Há, pois, um conjunto de normas jurídicas constitucionais, convencionais, legais e infralegais (decretos, resoluções e portarias) que estabelecem preceitos e procedimentos a serem observados pelos setores privados e públicos no âmbito de suas atividades e competências. Mas há, igualmente, inúmeras normas e procedimentos técnico-científicos que pautam as atividades empreendedoras, em seus múltiplos segmentos e especialidades nos setores primários, secundários e terciários. Tais diretrizes resultam de reflexões e experimentações da comunidade científica e que se submetem a processos de verificabilidade e de falibilidade técnico-científica (POPPER, 1974). Concomitantemente, debates e reflexões éticas, sob o prisma da filosofia moral, norteiam as expectativas de muitos cidadãos e grupos sociais que, atualmente, demandam mudanças comportamentais dos agentes privados e públicos em suas atividades empreendedoras e funções estatais. Pensadores clássicos (ex.: Platão, Aristóteles, Agostinho, Kant) e contemporâneos (ex.: Habermas, Lévinas, Jonas, Rawls, Ricoeur e Honneth) suscitaram princípios morais fundantes da relação ser humano/ 
meio ambiente e que precisam ser incorporados na dinâmica empreendedora privada e pública para alcançarem graus satisfatórios de accountability e responsiveness no contexto das sociedades plurissistêmicas (COSTA; REIS; OLIVEIRA, 2016), ainda que não exigíveis pelo sistema jurídico ou mesmo pendentes de verificabilidade pelo sistema técnico-científico.

O instituto do compliance ambiental envolve três níveis de integridade comportamental no âmbito da atividade empreendedora: a) a internalização de normas e procedimentos de adequação às normas jurídicas, éticas e técnico-científicas de sustentabilidade; b) o enforcemen $t$ (aplicabilidade e executoriedade) de normas e procedimentos internalizados; c) adoção de sistemas de solução de conflitos entre normas e procedimentos internalizados (entre si) e entre estes e as normas e procedimentos externos plurissistêmicos (SANDS; PEEL; FABRA; MACKENZIE, 2012, p. 135-183).

No modelo federativo brasileiro, em que todos os três níveis estatais estão constitucionalmente autorizados a legislar e a administrar questões relacionadas ao direito ambiental, a internalização de normas e procedimentos pela atividade empreendedora privada e pública requer a observância minuciosa do princípio da subsidiariedade, de maneira a evitar conflitos com os respectivos sistemas jurídicos federativos em seus níveis nacional, regional e local (OLIVEIRA, 2016, p. 376-377; CUSTÓDIO; OLIVEIRA, 2015). Concomitantemente, referenciais éticos relacionados ao mercado e às expectativas da sociedade plurissistêmica também devem ser considerados na adoção de normas e práticas de proteção ambiental e de inclusão socioeconômica. Ademais, a estrita adequação a padrões técnicocientíficos que possam conduzir a algum grau de segurança ambiental torna-se absolutamente indispensável no contexto da sociedade de risco pós-industrial (BECK, 2011).

Assim, a remodelagem da atividade de produção e circulação de bens e a de prestação de serviços passam a demandar a introdução de novas técnicas e procedimentos de observância de normas e processos de proteção ambiental. Por conseguinte, a atividade empreendedora privada e pública deve se pautar pela coleta e disponibilização de informações sobre o impacto ambiental real e potencial. Paralelamente, os setores públicos e privados precisam se conectar à sociedade por intermédio de instrumentos de transparência e publicidade de dados, bem como aprimorar seus sistemas de auditoria. Além disso, torna-se necessária a permanente reavaliação interna da governança pública e privada quanto aos temas ambientais, 
acrescida da constante atualização de práticas de formação, informação e treinamento de funcionários.

O enforcement (aplicabilidade e executoriedade) de normas e procedimentos internalizados deve viabilizar a ampliação do grau e do alcance do controle interno, não só pela atividade de fiscalização e responsabilização, mas, sobretudo, pelo estímulo a práticas e hábitos ambientalmente sustentáveis. No que concerne ao controle externo (Estado e sociedade), o enforcement também deve ser aprimorado com a finalidade de se promover ciclos de ação estatal e social não apenas de natureza punitiva, reparatória e restaurativa, mas primordialmente informativa, preventiva e incentivadora do empreendedorismo sustentável (WINDHAM-BELLORD, 2015).

$\mathrm{Na}$ criação de normas e procedimentos internos de sustentabilidade da atividade empreendedora, a pessoa jurídica necessita estabelecer meios e métodos de solução de conflitos entre normas e procedimentos internalizados (entre si) e entre estes e as normas e procedimentos externos plurissistêmicos. Por exemplo, quando normas internas de sustentabilidade conflitarem entre si ou com normas do sistema jurídico, ou com normas éticas ou até mesmo com normas técnico-científicas, há que se considerar aquela que promover a maior sustentabilidade possível. Como a noção de sustentabilidade conduz à prevalência da norma (substantiva ou processual) que resulte em maior proteção ambiental com maior inclusão socioeconômica, é plausível que a norma interna possa até mesmo prevalecer sobre a norma externa (jurídica, ética ou técnico-científica), em razão de seu grau de precaução ou de prevenção de dano eventual.

Por conseguinte, instrumentos de mediação e de sindicância, por exemplo, devem considerar as especificidades do segmento empreendedor e devem conjugar praticidade, agilidade e previsibilidade de garantias para investigados e investigadores nos processos de apuração e responsabilização interna por descumprimentos das normas e procedimentos do compliance. Ademais, e sempre que possível, a atividade empreendedora deve também estabelecer critérios de colaboração com órgãos estatais e da sociedade civil organizada que detenham competência fiscalizadora e responsabilizadora.

Há que se prestigiar, ainda, as implementações de selos de integridade quanto ao grau de sustentabilidade da atividade empreendedora. Portanto, os setores público e privado, em seus diversos segmentos, 
poderiam estimular a prática do compliance de sustentabilidade, de modo que, para cada setor, houvesse selos de qualificação, por intermédio dos quais não só a atividade de fiscalização seria facilitada, mas, especialmente, se concederiam meios de acesso a financiamentos com encargos menos onerosos para as atividades empreendedoras mais bem-ranqueadas.

No sentido abordado acima, tais empreendimentos poderiam obter maior alongamento de prazos para pagamento de dívidas públicas e privadas, bem como facilitação para a contratação com o setor público, dentre outros tantos benefícios que o mercado poderia regular positivamente. As práticas de integridade sustentável, avaliadas por selos públicos e privados, estimulariam boas formas de competição entre fornecedores e poderiam resultar também em maior conscientização dos consumidores.

Logo, atividades empreendedoras com alto grau de integridade no quesito da sustentabilidade poderiam alterar a dinâmica da atividade econômica, impactando positivamente nos hábitos sociais e culturais, no médio e longo prazos. Os setores mais poluentes (como a indústria de mineração) e as atividades culturais (como teatros e eventos musicais) passariam a ser mercadologicamente valorados de acordo com o ranqueamento público e privado de suas práticas de compliance sustentável.

Assim, não só o Estado criaria selos de sustentabilidade, como cada setor da economia, por meio de suas associações, também o faria. A competição em prol da obtenção de um maior ranqueamento no grau de sustentabilidade teria fortes reflexos pedagógicos, tanto na ampliação da consciência ambiental da sociedade como na fomentação da pesquisa científica e tecnológica, para se alcançar padrões de sustentabilidade cada vez mais apurados.

Fica evidente, portanto, que uma maior excelência nas práticas de sustentabilidade reduziria, por exemplo, gastos públicos com a despoluição e com o conjunto de políticas públicas de tratamento de resíduos, manutenção de infraestrutura sanitária e até de saúde pública. Paralelamente, a atividade empreendedora reduziria os riscos de responsabilização por danos ambientais e, numa alternância de cultura de consumo, teria ampliado o seu mercado de fornecedores e consumidores, igualmente comprometidos com a obtenção ou com a observância de selos de sustentabilidade.

Enfim, uma nova economia, sob a afirmação de uma cultura de integridade mais sustentável, poderia ser viabilizada a partir do compliance. É fato que apenas a adoção de instrumentos de compliance nas atividades 
empreendedoras públicas e privadas não é suficiente para a alteração de uma cultura de produção e consumo pouco sustentável para uma cultura de maior sustentabilidade. Entretanto, o instituto do compliance tem potencial para colaborar, de modo eficiente, na formação e na afirmação da sustentabilidade, à medida que segmentos inteiros passem a adotá-lo como instrumento de avaliação da governança sustentável.

A médio e longo prazos, a cultura da sustentabilidade tornar-seia paradigma dominante nas atividades de produção de bens e de prestação de serviços, em todos os setores primários, secundários e terciários da economia, e em atividades empreendedoras tanto públicas quanto privadas. Havendo alternância no ciclo da produção, concomitantemente haveria repercussão positiva nos ciclos da distribuição, da repartição e do consumo, o que resultaria, por certo, em maior grau de sustentabilidade.

\section{CONSIDERAÇÕES FINAIS}

A busca pelo empreendedorismo ambiental e socioeconomicamente sustentável é tema da maior relevância no atual contexto do desenvolvimento dos povos. É fato que a produção e a distribuição da riqueza, bem como o acesso ao consumo de bens e serviços necessitam alterar seu paradigma de dominação e exploração da natureza para o da economia sustentável. O progresso obtido pela ciência e tecnologia ao longo da modernidade não foi capaz de conciliar a humanidade com o meio-ambiente. Entretanto, a civilização encontra-se em risco de extinção, caso não altere sua cultura depredatória para a cultura de integridade ambiental.

O presente artigo partiu dessa constatação, atualmente analisada em diversos estudos acadêmicos e objeto de vários relatórios de instituições nacionais e internacionalmente prestigiadas, para discorrer acerca do instituto do compliance. Ao longo do trabalho, foi abordado o tema da pluralidade, da complexidade e da dinamicidade das sociedades contemporâneas plurissistêmicas e, sob este pressuposto, o compliance foi tratado como instituto capaz de conciliar a multiplicidade normativa que incide sobre as atividades empreendedoras públicas e privadas. Em seguida, o instituto do compliance foi abordado como elemento de boa governança e de gestão social e como fator para a promoção de maior accountability e responsiveness do empreendedorismo público e privado.

Ao se discorrer sobre o instituto do compliance na seara 
da sustentabilidade ambiental e socioeconômica, pode-se aferir que o compliance detém potencialidade para atuar de modo relevante na formação e na afirmação de uma cultura de integridade sustentável. Pela adoção de instrumentos de compliance ambiental e socioeconômico, as atividades empreendedoras públicas e privadas podem, por consequência, alterar, no médio e longo prazos, o paradigma predatório para o da sustentabilidade da produção de bens e de prestação de serviços, com consequente repercussão positiva nos ciclos econômicos da distribuição, da repartição e do consumo. Nesse sentido, a hipótese da qual partiu o trabalho restou plenamente comprovada em termos teórico-especulativos.

\section{REFERÊNCIAS}

ALCÂNTARA, Valderí de Castro; PEREIRA, José Roberto; SILVA, Érica Aline Ferreira. Gestão social e governança pública: aproximações e (de) limitações teórico-conceituais. Revista de Ciências da Administração, v. 17, Edição Especial, p. 11-29, 2015. Disponível em: <http://www.redalyc. org/pdf/2735/273543118001.pdf $>$ Acesso em 26 de julho de 2018.

BECK, Ulrich. A sociedade de risco; rumo a uma outra modernidade. São Paulo: Editora 34, 2011.

BRESSER-PEREIRA, Luiz Carlos. Administração pública gerencial: estratégia e estrutura para um novo Estado. Texto para Discussão no 9. Brasília, MARE/ENAP, 1996.

CGU - Controladoria-Geral da União. Guia de implantação de programa de integridade nas empresas estatais: orientações para a gestão da integridade nas empresas estatais federais. Disponível em: <http://www. cgu.gov.br/Publicacoes/etica-e-integridade/arquivos/guia_estatais_final. pdf $>$. Acesso em 15 de agosto de 2018.

COSTA, Beatriz Souza; REIS, Émilien Vilas Boas; OLIVEIRA, Márcio Luís de. Fundamentos filosóficos e constitucionais do direito ambiental. Rio de Janeiro: Lumen Juris, 2016.

COSTA, Beatriz Souza; MATA DIZ, Jamile B.; OLIVEIRA, Márcio Luís de. Cultura de consumismo e geração de resíduos. Revista Brasileira de Estudos Políticos (Belo Horizonte), n. 116, jan./jun. 2018, p. 159-183. Disponível em: <https://pos.direito.ufmg.br/rbep/index.php/rbep/article/ 
view/570/451\#>. Acesso em 27 de julho de 2018.

CUSTÓDIO, Maraluce Maria; OLIVEIRA, Márcio Luís de. Eco-efficiency in bidding processes to purchase everyday supplies for the Brazilian federal administration.Veredas do Direito, Belo Horizonte, v.12, n.24, p.33-61, Jul/Dez 2015. Disponível em: <http://www.domhelder.edu.br/revista/ index.php/veredas/article/view/647/454>. Acesso em 5 de julho de 2018.

HOLLAND, Alan. Sustainability, p. 390-401. In.A companion do environmental philosophy.Blackwellcompanionstophilosophy. Oxford: DaleJamieson, editor, 2001.

MENDONÇA, Cláudio Márcio Campos de; GUERRA, Lenin Cavalcanti Brito; SOUZA NETO, Manuel Veras de; ARAÚJO, Afrânio Galdino de. Governança de tecnologia da informação: um estudo do processo decisório em organizações públicas e privadas. Revista de Administração Pública [Rio de Janeiro], $\mathrm{n}^{0}$ 47, v. 2, p. 443-468, mar./abr. 2013. Disponível em: <http://bibliotecadigital.fgv.br/ojs/index.php/rap/article/ view/8066/6855>. Acesso em 31 de julho de 2018.

OLIVEIRA, Márcio Luís de. União Européia; do processo de integração econômico-política à formação de uma cidadania supraestatal comunitária. Belo Horizonte: UFMG/Faculdade de Direito, 1999 (Dissertação de Mestrado).

OLIVEIRA, Márcio Luís de. A Constituição juridicamente adequada. 2. ed. Belo Horizonte: D'Plácido, 2016.

POPPER, Karl. A lógica da pesquisa científica. São Paulo: Cultrix, 1974.

SANDS, Philippe; PEEL, Jacqueline; FABRA, Adriana; MACKENZIE, Ruth. Principlesofinternationallaw. Cambridge: Cambridge University Press, 2012.

SEBRAE -Serviço Brasileiro de Apoio às Micro e Pequenas Empresas. Disponível em: <http://www.sebrae.com.br/sites/PortalSebrae/bis/comoelaborar-um-planejamento-estrategico,854836627a963410VgnVCM1000 003b74010aRCRD $>$. Acesso em 26 de julho de 2018.

SILVA, Cristiana Maria Fortini Pinto e; VIEIRA, Ariane Shermam Morais. Lei anticorrupção empresarial: os riscos na sua regulamentação 
e implementação. In: DIAS, Maria Tereza Fonseca; REPOLÊS, Maria Fernanda Salcedo (Org.). O direito entre a esfera pública e a autonomia privada: transformações do direito público no ambiente democrático. 1. ed. Belo Horizonte: Fórum, 2015.

SOUZA, Washington Peluso Albino. Primeiras linhas de direito econômico. São Paulo: LTr, 2005.

THE WORLD BANK.Governance and Development. Washington,D. C.: World Bank Publication, 1992. Disponível em: $<$ http://documents. worldbank.org/curated/pt/604951468739447676/pdf/multi-page.pdf $>$. Acessoem 25 de julho de 2018.

THE WORLD BANK. What is Governance?Arriving at a Common Understanding of “Governance”. 2009. Disponível em:

$<$ http://web.worldbank.org/archive/website01020/WEB/0_CON-5. HTM $>$. Acesso em 26 de julho de 2018.

WALKER, James. Compliance: origem, evolução histórica e legislativa. IBC - Instituto Brasileiro de Compliance, 2016. Disponível em: <http:// ibcompliance.com.br/index.php/ebook-gratuito-compliance-origemevolucao-historica-e-legislativa/> . Acesso em 23 de setembro de 2018.

WILSON, Robert H. Understanding local governance: aninternational perspective. ERA - Revista de Administração de Empresas. São Paulo, v. 40, n. 2, p. 51-63, abr./jun. 2000. Disponível em: <http://www.scielo.br/ $\mathrm{pdf} / \mathrm{rae} / \mathrm{v} 40 \mathrm{n} 2 / \mathrm{v} 40 \mathrm{n} 2 \mathrm{a} 06 . \mathrm{pdf}>$. Acesso em 23 de julho de 2018.

WINDHAM-BELLORD, Karen Alvarenga de Oliveira. Direito ambiental, economia verde e conservação da biodiversidade. Belo Horizonte: D’Plácido, 2015.

\section{Como citar este artigo (ABNT):}

OLIVEIRA, Marcio Luis; COSTA, Beatriz Souza; PINTO E SILVA, Cristiana Maria Fortini. O INSTITUTO DO COMPLIANCE AMBIENTAL NO CONTEXTO DA SOCIEDADE PLURISSISTÊMICA. Veredas do Direito, Belo Horizonte, v. 15, n. 33, p. 51-71, set./ dez. 2018. Disponível em: <http://www.domhelder.edu.br/revista/ index.php/veredas/article/view/1396>. Acesso em: dia mês. ano.

Artigo recebido em: 23/10/2018.

Artigo aceito em: 20/11/2018. 